\title{
POLARIZATION AND INTERNAL RESISTANCE OF ELECTROLYTIC CELLS. I.
}

By Martin D. Atkins.

Introductory Note on the Polarization-Capacity of Electrohytic Cells. ${ }^{1}$

$T^{\mathrm{T}}$ is well known that an electrolytic cell behaves like a condenser, or better, two condensers in series, a difference of potential being produced by the passage of a quantity of electricity. In general

$$
c \frac{d p}{d t}=i
$$

$c$ is called the polarization capacity and is obviously a variable quantity becoming infinitely large after a certain maximum limit of polarization has been reached. On the other hand $c$ has a definite value when the time $t$, during which the current is flowing is decreased to zero. This value seems to be of importance and is called the "initial capacity" or short "the polarization capacity" of a cell.

Apparently the polarization-capacity may be approximately determined by alternating current methods. Varley, ${ }^{2}$ M. Wien, ${ }^{3}$ Gordon, ${ }^{4}$ Neumann ${ }^{5}$ and many others have worked on this problem and though their results are not in absolute agreement, it may be asserted that every metal has a definite "initial polarization capacity" with electrolytic solutions. Concentration and temperature of solution have some influence upon its value, and here the different experimenters arrive at widely different results, a great many disturbing factors entering into the process. So far only small polarization capacities, principally $\mathrm{Pt}$ and $\mathrm{Hg}$ in $\mathrm{H}_{2} \mathrm{SO}_{4}$ have been measured.

By knowing the exact formula for polarization as a function of the time and determining the constants, we will be able to calculate the

${ }^{1}$ By K. E. Guthe.

2 Proc. Roy. Soc., 1871 .

3 Wied. Ann., 58, p. 37, I896.
${ }^{4}$ Wied. Ann., 6r, p. I, I897.

5 Wied, Ann., I899. 
capacity of a cell from these data. Wiedeburg has done so by making use of Bartoli's experiments on $\mathrm{Pt}$ in $\mathrm{H}_{2} \mathrm{SO}_{4}$ and found a result agreeing quite closely with Kohlrausch's direct results.

In a former paper ${ }^{1}$ I have been able to show that Bartoli's empirical formula, being the same as one derived by Wiedeburg from a few theoretical suppositions, explains the apparent change of the internal resistance with different current densities, very often attributed to a "resistance of transition."

This formula has the simplified form

$$
p=P\left(\mathrm{I}-e^{-a q}\right)
$$

where $P$ is a constant, "the maximum polarization," $a$ a constant depending on the size of the electrodes and $q$ the quantity of electricity having passed through the cell.

By a simple arrangement of the apparatus, namely by using an E.M.F. very large in comparison with $P$ and using a large noninductive resistance in series with the cell we were able to have a constant current through the cell during one observation, such that we could employ the formula

$$
\rho I=r I+P\left(\mathrm{I}-e^{-K I}\right)
$$

where $\rho$ is the apparent and $r$ the real resistance of the cell. In the paper mentioned $\mathrm{I}$ have shown that this formula represents the resistance curve obtained for $\mathrm{Cu}$ in $\mathrm{CuSO}_{4}$.

The same method enables us to determine the polarization capacity of the electrolytic cell and this method is also very well applicable to cells of very large polarization capacities, as those of the so-called unpolarizable electrodes.

It follows from equation ( $\mathrm{I}$ ) that the polarization capacity is

and the initial capacity

$$
c^{\prime}=\frac{e^{a \imath t}}{P a}
$$

or using formula (2)

$$
c=\frac{\mathrm{I}}{P a}
$$

$$
c=\frac{t}{P K} \cdot
$$

1 Phys. Rev., 7, p. 193, 1898. 
From the values of $P$ and $K$ calculated from the curves and knowing the time $t$ and the area of the electrodes we can easily determine the capacity of unit area of the electrodes.

I wish to correct a slight error, which occurs in my former paper. From equation (2) we see that for very large currents the apparent resistance equals the real resistance of the cell. For zero current $\rho-r=P K$, or the curve will cut the $Y$ axis, on which the $\rho$ 's are plotted at a distance equal to $P K$ above the real resistance.

We have therefore here a constant current method for finding the polarization capacity of an electrolytic cell, applicable also to large capacities, which cannot be determined by alternating current methods.

On the other hand all the disturbing influences, which have been found by other observers, will be noticeable here. This method may therefore be used to a great advantage in the study of the changes going on in an electrolytic cell.

It will also enable us to throw some light on peculiarities, observed in researches on the resistance of transition.

Mich. Univ. Physical Laboratory, June, I899.

\section{Part I. Theory and Formulæ.}

Of the various theories, advanced in explanation of the phenomena observed in electrolytic cells, that of Wiedeburg ${ }^{1}$ is deserving of attention in that it is expressed in mathematical formulæ, and that it explains, by polarization alone, those various changes, attending the passage of an electric current through a cell, which, by other theories, have been ascribed to causes as various as the theories themselves. An investigation of this theory becomes then one of extreme interest ; since, should it be found to accord with the results of experiment, the question of what occurs within an electrolytic cell would be much simplified. An added interest has attached to this subject, since this investigation was begun, owing to the fact that Dr. Guthe has derived a formula, reducible to the exact form of that of Wiedeburg, from considering the polarization capacity alone. By making use of this derived formula and the hypothesis that the polarization capacity, for any given solution and electrodes, is constant, the method of this research becomes ap-

I Wiedeburg's Habilitationschrift, Leipzig, I893. Wied. Ann., 51, 302, 1894. 
plicable to the measurement of the polarization capacity of a given cell. ${ }^{1}$ This assumption is in agreement with the experimental results of several investigators, among whom may be mentioned: Herwig, I87I ; Blondlot, I88I ; Kohlrausch, I878; and others.

It was for the purpose of determining, if possible, the value of Wiedeburg's theory, and the application of the formulæ he derives, that this investigation was undertaken. It may be said to have had as its objective points the answering of these two questions: (a) "Is the change in the resistance of an electrolytic cell with varying current a real or an apparent change ?" (b) "Does the Wiedeburg theory, with its derived formulæ, satisfy the known conditions, and the characteristic curves, of this change?"

In a preliminary paper, ${ }^{2}$ making use of some of the first results of this research, Dr. Guthe has described the method employed and given a brief statement of the theory of Wiedeburg. In the interest of unity, however, these points may well be briefly treated here.

A statement of his fundamental hypotheses is given by Wiedeburg $^{3}$ as follows: "I assume that under all circumstances, even with extremely small electromotive forces, electrolysis occurs, viz : of such a nature that in general a part of the ions of the electrolyte, accumulating at the electrodes, is neutralized; $i$. e., undergoes chemical transformation with loss of its electric charge. This neutralization advances with a variable rapidity, in accordance with a law very similar to that of ordinary chemical reaction. The more numerous are the unneutralized, polarizing ions, accumulated before the electrodes, the more rapidly the further accumulation diminishes with the time; and the more rapidly, on the other hand, the neutralization (electrolysis) proceeds. The increasing polarization would soon produce a cessation of the migration of the ions, for every E.M.F. below its maximum, were it not that other processes, not electric in their nature, operate constantly to decrease it ; removing the ions, partly by transference to the interior of the electrodes

${ }^{1}$ Guthe and Atkins, Polarization and Polarization Capacity of Elect. Cells, Proceed. ings A. A. A. S., I 899, p. 109.

2 Polarization and Internal Resistance of Electrolytic Cells : Guthe, Phys. Rev., Vol. VII., No. $3^{8}$.

3 “Zur Frage nach dem Grundgesetz der Elektrolyse," O. Wiedeburg, Zeit. Phys. Chem., XIV., I., I894. 
-occlusion-partly by union with neutral dissolved substances, e. $g$., atmospheric oxygen. It is evident then that, even with an E.M.F. far less than a Daniell, by suitable arrangement of the apparatus, an actual electrolysis of 'acidulated water' may be brought about, increasing even to the point of the evolution of gas."

Let us now apply this theory to the simplest possible case, that of a metallic electrode in a solution of its own salt. If we pass through such a cell any current, of even the slightest E.M.F., the ions are swept to the respective electrodes, carrying their electric charges. Some of these ions pass at once to the electrodes, giving up to them their electricity, becoming themselves neutral and contributing nothing to the counter-electromotive force of polarization. Not all the charged ions however thus give up their electricity, some remaining heaped up before the electrodes. The difference in concentration thus produced results in the counter E.M.F. of polarization. The number of ions free at any instant, with any given solution and electrode, is proportional to the difference between the maximum concentration possible and that obtaining at the moment under consideration.

The formulæ derived from these suppositions by the author of this theory are the same as those of Bartoli ${ }^{1}$ upon whose experiments they are founded, viz:

$$
p=\frac{P_{1}}{2}\left(\mathrm{I}-e^{-\frac{\beta_{1} q}{S_{3}}}\right)+\frac{P_{2}}{2}\left(\mathrm{I}-e^{-\frac{\beta_{2} q}{S_{2}}}\right) .
$$

Here $p$ is the momentary value of the polarization, whose maximum values are denoted by $P_{1}$ and $P_{2}$, for the respective electrodes; $\beta_{1}$ and $\beta_{2}$ are constants depending upon the electrodes. $S_{1}$ and $S_{2}$ denote the areas of the electrodes; and $q$ the quantity of electricity that has passed through the cell.

In the case under consideration, since the electrodes are identical in kind and of equal areas, $\beta_{1}=\beta_{2}$ and $S_{1}=S_{2}$; and the formula simplifies to

$$
p=P\left(\mathrm{I}-e^{-\stackrel{\beta q}{-}}\right) \text {. }
$$

If now we make the times of each discharge through the cell very

${ }^{1}$ Wied. Elektricitat, Vol. II., 883. 
short, and the same for all currents, since $q=I t$ (II.) reduces to

$$
p=P\left(\mathrm{I}-e^{-\frac{\beta t I}{s}}\right) \text {. }
$$

Then for $\left(\frac{B t I}{S}\right)$ we may write $K I$, and equation (II.) becomes

$$
p=P\left(\mathrm{I}-e^{-E I}\right) \text {. }
$$

Deriving the expression for the current in accordance with Ohm's law we obtain

$$
I=\frac{E^{\prime}-P\left(\mathrm{I}-e^{-K I}\right)}{r} .
$$

Where $E^{\prime}$ is the applied E.M.F. at the terminals of the cell, and $r$ its internal resistance. Upon the assumption that no polarization has occurred in the time of passing the current, the apparent internal resistance $\rho$ is usually computed from the formula

$$
\rho=\frac{E^{\prime}}{I}
$$

Substracting (IV.) from (V.) gives equation (VI.), another form of equation (IV.)

$$
\rho-r=\frac{P\left(\mathrm{I}-e^{-K I}\right)}{I} .
$$

Inspection of this equation shows that the apparent resistance, as usually found by methods taking no account of the polarization, is larger than the real resistance $r$, found by this method in accordance with Wiedeburg's theory. In every case where comparison could be made with results obtained by the Kohlrausch method, this condition has been fulfilled; while the method has the advantage of applicability to those cases in which the latter method could not be used. Further inspection of equation (VI.) shows that for very large currents, and small polarization, $\rho$, the apparent, becomes equal to $r$, the real, internal resistance; while, for zero current, $\rho-r=K P$.

If the apparatus be of such sort that the times for several series of observations can be maintained the same, we may form the following series of equations :

$$
\rho_{1}-r_{1}=\frac{P\left(\mathrm{I}-e^{-K I_{\mathrm{a}}}\right)}{I_{1}}
$$


(VIII.)

$$
\rho_{2}-r_{2}=\frac{P\left(\mathrm{I}-e^{-K I_{2}}\right)}{I_{2}}, \text { etc. }
$$

If now we assume $r_{1}=r_{2}$ we obtain, by combining three observations, the following equations

$$
\begin{gathered}
P=\frac{E_{1} I_{2}-E_{2} I_{1}}{I_{2}\left(\mathrm{I}-e^{-K I_{1}}\right)-I_{1}\left(\mathrm{I}-e^{-K I_{2}}\right)} \\
\frac{E_{1} I_{2}-E_{2} I_{1}}{E_{2} I_{3}-E_{3} I_{2}}=\frac{I_{2}\left(\mathrm{I}-e^{-K I_{1}}\right)-I_{1}\left(\mathrm{I}-e^{-K I_{2}}\right)}{I_{3}\left(\mathrm{I}-e^{-K I_{2}}\right)-I_{2}\left(\mathrm{I}-e^{-K I_{3}}\right)}=Q .
\end{gathered}
$$

The values of $E$ and $I$ can be computed from the observed data and the quotient $Q$ thus determined. $K$ is then computed by successive substitutions until the assigned value satisfies the second member of the equation. In practice, usually, values were found for $K$ which gave values for $Q$, lying near, but both above and below, the required value. By plotting a curve then, with the assigned value of $K$ and resulting quotients, $Q$, the value required, could be taken from the curvs. Equation (IX.) could then be solved for $P$. Evidently, were there nothing to indicate the region to be explored for the value of $K$, such a method, involving a large expenditure of time and a wearisome amount of computation, would be of little practical value. Fortunately it is possible to obtain at once, in most cases, approximate values for both $K$ and $P$.

Inspection of equation (IX.) shows us that, in case of large currents, with $K$ large, as it is when the electrodes are small, the factor $\left(\mathrm{I}-e^{-K I}\right)$ is approximately equal to $\mathrm{I}$. If then we make use of observations taken with large currents, we may use equation (IX.) in this modified form.

$\left(\right.$ IX. $\left.{ }^{\text {a }}\right) \quad P=\frac{E_{1} I_{2}-E_{2} I_{1}}{I_{2}-I_{1}}$, which gives us $P$ at once.

There are then two methods for obtaining approximate values for $K$. (I) We may compute $r$ for all currrents, beginning with the largest used, and taking an average from such values as do not largely differ. With this mean value, and the observations made with smallest currents, we may compute $K$ from equation (VI.).

$$
\rho-r=\frac{P\left(\mathrm{I}-e^{-K I}\right)}{\mathrm{I}}
$$


(2) From an observation with large current combined with one when the current is small we obtain

$$
\begin{gathered}
r=\frac{E_{1}-P}{I_{1}}=\frac{E_{2}-P\left(\mathrm{I}-e^{-K I_{2}}\right)}{I_{2}} \text { which solved for } K \text { gives } \\
\left.K=\frac{\log \left\{\frac{P}{\frac{I_{2}}{I_{1}}\left(E_{1}-P\right)-\left(E_{2}-P\right)}\right.}{I_{2} \log e}\right\}
\end{gathered}
$$

Having, by either of these methods, approximate values for $K$ and $P$, the solution, by successive substitutions and the use of the curve, becomes less difficult. The latter of these methods was the one employed almost exclusively, in the second part of this investigation, in every case where $K$ was sufficiently large to render it applicable.

It may be said in further explanation of the formulæ, that, with the high applied E.M.F.-from 66 to 82 volts-employed in these experiments, and the small values obtained for the polarization-in only one case exceeding 0.2 of a volt-the assumption that $I$ in any case does not vary while the current is flowing is certainly correct to a degree far within the limits of negligible error.

\section{The Apparatus and Method.}

The apparatus used was the pendulum apparatus designed by Professor Henry L. Carhart ${ }^{1}$ and the arrangement was that shown in the accompanying diagram (Fig. I). The pendulum when released struck and overturned in order keys I. to IV., causing a current from the storage battery $B$, with an E.M.F. of from 66 to 82 volts, to flow through the electrolytic cell $E$ during the passage of the pendulum between these points. When key II. was thrown by the pendulum in its passage the condenser $K$ was charged at will-as determined by the commutator $C$-with either the difference of potential between the electrodes, or that between the terminals of the known resistance $R$. This resistance was made nearly equal to that

${ }_{1}$ Phys. Rev., II., 392, I895 ; Carhart \& Patterson, Elect. Measurements, p. 106. 
of the cell under investigation, to eliminate possible errors which might arise from widely diverging deflections of the galvanometer. The condenser was discharged through the galvanometer $G$ when key III. was overthrown. The condenser used was one which careful tests had found approximately free from leakage and absorption. The constant (IO2.I) for the ballistic galvanometer, had been many times carefully determined. Deflections were read from the image of an aperture and crosswire upon a ground-glass scale; and, by the use of reading lenses, could be easily determined to tenths of a scale

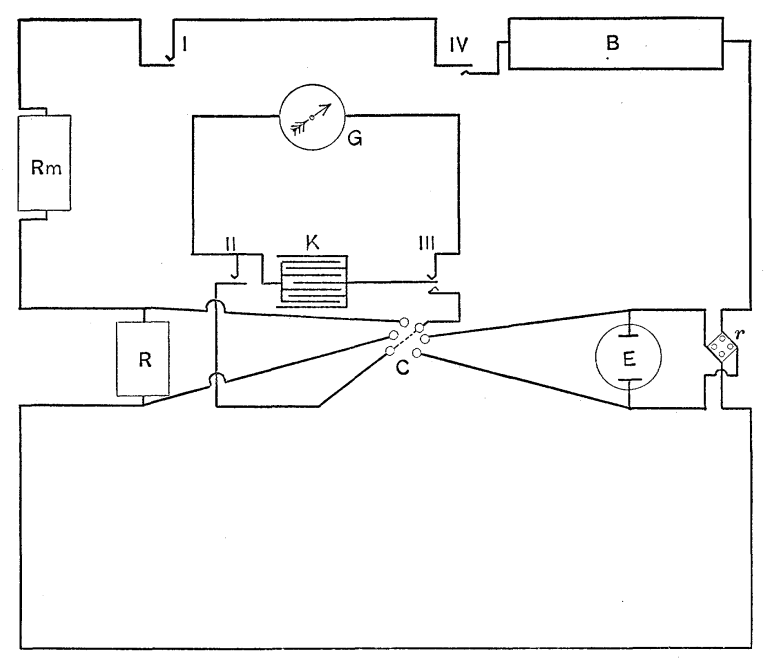

Fig. 1.

division. Later in the investigation, after the eye had become accustomed to the work, it was found possible to dispense with these lenses.

Several points of possible error, which suggested themselves, were the subjects of preliminary investigation. It was thought possible that, with the smallest currents used, there might be a loss in charging the condenser ; or that it might not fully charge in the short interval allowed for this purpose. To determine the first of these points a key was placed in the galvanometer circuit. The pendulum was then allowed to swing, charging the condenser, but without 
discharging it. It was then charged again and allowed to discharge as usual through the galvanometer. Readings, thus obtained, did not differ from those obtained by the single charging of the condenser. To determine the second point, the time of charging the condenser was varied largely, key II. being even placed before key I., so that the condenser was in circuit before the current began to flow. The results did not change. It was then evident that the condenser was fully charged, even by the smallest currents, and that there was no loss upon these currents within the condenser and its circuit.

To eliminate adventitious potential differences, either within the cell or condenser, keys, not shown in the diagram, were introduced, by means of which both were kept short-circuited until the instant of releasing the pendulum.

Although the current was allowed to flow for such short intervals, it was found that, with some cells, a marked polarization gradually established itself. To eliminate this, together with possible errors in the galvanometer, a reversing key, $r$, was introduced, by means of which the cell could be depolarized, or the readings tested, if desired.

A somewhat extended, though unsatisfactory, investigation, made early in the work, seemed to indicate that temperature changes had very little influence upon the nature of the curves obtained. An example of this is seen in the two curves for bright platinum electrodes (in $\mathrm{H}_{2} \mathrm{SO}_{4}$ ), shown in Plate III., No. I. It will be seen that, with so great a difference in temperature as $\mathrm{I} 7$ degrees, the curves, reduced to the same resistance, are nearly identical. Although a further investigation of this question is intended, and necessary, before an authoritative statement can be made as to the effect of temperature upon the constants, it is quite certain that such small changes as may have occurred in the course of an investigation, rarely reaching 1.5 degrees, could have had no appreciable influence upon the results. Precautionary measures were always taken, by using large amounts of the solutions (from 2 to ro liters), and by placing the cells in a constant temperature bath. By this means, also, irregularities due to variations in density, convection currents, etc., were reduced to a minimum. 


\section{Preliminary Investigation of $\mathrm{CuSO}_{4}$ Between Copper Elec-} TRODES.

Since in the preliminary investigation, already reported by Dr. Guthe, copper electrodes in a solution of $\mathrm{CuSO}_{4}$ had been employed, with results in such seeming accord with the theory, the first step in this investigation was a repetition of the observations with these materials. Copper electrodes $10 \times$ I $3 \mathrm{~cm}$. were used, insulated-as were all plates investigated-upon the back with a coating of beeswax. The solution was prepared by dissolving 25 grammes of C. P. copper sulphate in I liter of distilled water at $20^{\circ}$. It became very soon evident that the results obtained depended upon how long the electrodes had been in the solution. So an experiment was made to determine, if possible, the reasons for the irregularities observed. Successive observations were taken; one, immediately after placing the plates in the solution; another, after two and one-half hours; and a third, after twenty-four hours. The three curves, for the change in apparent resistance $(\rho)$ with the current $(I)$, are shown in Plate II., Fig. I, Nos. I., II., III. Since it seemed probable that the great increase in apparent resistance was due to oxidation, it is of interest to note that, despite the great disparity in range of the three curves, they start at the same point; $i$. e., the actual resistance $r$ is the same in each case. This fact indicates that it is not really an increase in resistance, due to a badly conducting film of copper oxide, as has been said, but, rather, an effect due to polarization and its conditions. A possible explanation of this change will be given later, in the general discussion of the results. From the tables of results which follow, it may be seen that, while the first curve is well satisfied by our formulæ, the second is less, and the third still less, in agreement therewith.

The notation employed in these, as in all tables to be given hereafter, is the following: Cap., in the first column, denotes the capacity of the condenser in Micro-Farads; $d C$, the galvanometer deflection upon the cell ; $d R$, the same upon the resistance. $I$ signifies the current in ampères ; $\rho$, the apparent resistance in ohms; $r$, the internal resistance computed according to the Wiedeburg formula; $P$, the maximum value of the polarization in volts; $\left(\mathrm{I}-e^{-K I}\right)$, the correction factor. 
To avoid the errors arising from taking small differences of values from observations lying adjacent, it has been the custom in all these computations to divide the observations into two groups, as has been done here, e. $g ., P$ is computed from I, $4 ; 2,5 ; 3,6$ and 4 , 7 respectively.

\section{TABLE I.}

I. Oxidation Curve, $\mathrm{Cu}$ in $\mathrm{CuSO}_{4}$. Nov. 19. $T=25.5^{\circ} ; R=5$ ohms. Electrodes $10 \times 13 \mathrm{~cm}$. Solution 25 G. in 1 L. $K=20 ; P=.056 ; K P=1.12$.

\begin{tabular}{c|c|c|c|c|c|c|c}
\hline \hline Cap. & $d C$ & $d R$ & $I$ & $\rho$ & $\left(\mathrm{I}-e^{-K X}\right)$ & $r$ & $P$ \\
\hline 0.1 & 176.3 & 160.3 & .6200 & 5.50 & 1.0000 & 5.41 & \\
0.2 & 187.5 & 168.0 & .3291 & 5.58 & .9983 & 5.41 & \\
0.6 & 245.7 & 212.0 & .1385 & 5.80 & .9019 & 5.42 & \\
1.0 & 212.8 & 177.0 & .0693 & 6.01 & .7395 & 5.42 & .0564 \\
$،$ & 108.5 & 87.0 & .0341 & 6.24 & .4829 & 5.44 & .0589 \\
$،$ & 44.5 & 35.0 & .0137 & 6.36 & .2335 & 5.41 & .0547 \\
$،$ & 28.0 & 21.9 & .0086 & 6.39 & .1583 & 5.40 & .0530 \\
\hline
\end{tabular}

TABLE II.

I1. Oxidation Curve, after $21 / 2$ hours. Nov. 19. $T=26.1^{\circ} ; R=5$ ohms. Electrodes and solution undisturbed. $K=30.56 ; P=.101 ; K P=3.09$.

\begin{tabular}{l|r|r|r|r|r|r|c}
\hline Cap. & $d C$ & $d R$ & $I$ & $\rho$ & $\left(\mathrm{r}-e^{-K I}\right)$ & $r$ & $P$ \\
\hline 0.1 & 178.0 & 161.0 & .6307 & 5.53 & 1.0000 & 5.37 & \\
0.2 & 194.7 & 169.5 & .3320 & 5.74 & 1.0000 & 5.44 & \\
0.6 & 265.5 & 213.0 & .1391 & 6.23 & .9853 & 5.41 & \\
1.0 & 238.3 & 177.7 & .0696 & 6.70 & .8808 & 5.44 & .1067 \\
& 127.8 & 87.5 & .0343 & 7.30 & .6492 & 5.39 & .0975 \\
& 54.8 & 34.7 & .0136 & 7.90 & .3399 & 5.38 & .0979 \\
3.2 & 109.0 & 67.0 & .0082 & 8.13 & .2219 & 5.40 & \\
\hline
\end{tabular}

It is unnecessary to give the data for the third oxidation curve, as the changes there have become so great that the formula no longer gives any satisfactory results. While, in general, the changes are in the same direction- $K$ having increased to about 46 and $P$ to $.2 \mathrm{I}$ - the values obtained for $r$ vary much more widely than the allowable amount from the constant value demanded by the formula.

Another observation, with the same solution and another pair of electrodes, is given here, for purposes of comparison. ${ }^{1}$

${ }^{1}$ See also Tables XXVII.-XXVIII. of this paper. 
TABLE III.

Copper Electrodes in $\mathrm{CuSO}_{4}(25$ G. in 1 L. $)$. Nov. 26. $T=23.0^{\circ} ; R=5.0$ ohms; $K=30 ; P=.054 ; K P=1.62$.

\begin{tabular}{c|c|c|c|c|c|c|c}
\hline Cap. & $d C$ & $d R$ & $I$ & $\rho$ & $\left(\mathrm{x}-e^{-K I}\right)$ & $r$ & $P$ \\
\hline .10 & 187 & 164 & .6425 & 5.70 & 1.0000 & 5.62 & \\
.25 & 251 & 216 & .3385 & 5.81 & 1.0000 & .65 & \\
.50 & 210 & 173 & .1356 & 6.08 & .9283 & .67 & \\
1.00 & 220 & 174 & .0682 & 6.32 & .8708 & .63 & .0549 \\
3.20 & 370 & 278 & .0341 & 6.67 & .6400 & .63 & .0531 \\
& 156 & 111 & .0136 & 7.03 & .3350 & .65 & .0549 \\
& 95 & 66.5 & .0082 & 7.14 & .2178 & .65 & \\
\hline
\end{tabular}

The curve, for observed and calculated values for $\rho$, for a set of observations with copper in $\mathrm{CuSO}_{4}$, is given on Plate III., No. 2. It will be seen that again, as in the former investigation with these materials, ${ }^{1}$ there is good agreement between the values thus obtained. While it was evident, then, that with copper electrodes, freshly introduced into a solution of copper sulphate, results in agreement with the theory of Wiedeburg could be obtained, it was desirable, in order that extended observations might be made, that a metal be used less subject to the disturbing influence here encountered. Upon the supposition that this was due to oxidation, the next metal tried was silver, in a solution of silver nitrate.

Observations with Silver in Silver Nitrate.

Into a solution of $\mathrm{AgNO}_{3}, \mathrm{IOO} \mathrm{g}$. in I liter at $20^{\circ}$, the electrodes, silver plates, $7.9 \times 12 \mathrm{~cm}$., were introduced and successive observations made, as had been done with the copper. These observations extended through a period of five days; and showed a similar increase in the range of apparent resistance. The longer the plates remained in the solution, the greater this range became, as will be seen by the following table.

TABLE IV.

Silver in $\mathrm{AgNO}_{3}$. Time change in $\rho$.

\begin{tabular}{c|c|c|c|}
\hline $\begin{array}{c}\text { No. of } \\
\text { Observation. }\end{array}$ & Interval. & Range of Apparent Resistance. \\
\hline 1 & 53 min. & 1.11 to 3.40 i. e., 2.29 ohms. \\
\hline 2 & 4 hours. & 1.12 to 4.88 "6 3.76 " \\
3 & 60 & "6 & 1.19 to 5.45 " 4.26 " \\
4 & 74 & "6 & 1.11 to 6.42 " 5.31 " \\
\hline
\end{tabular}

${ }^{1}$ Guthe, K.E., Phys. Rev., Vol. VII., p. 197. 
It is to be noted that here again, as with the copper, there is no increase in the real resistance. Correcting for temperature the curves all start at the same point; while the range through which the apparent resistance changes is more than doubled. That this phenomenon is due to oxidation is impossible; for, as far as could be detected, the plates were as clean and bright at the end of the test as when placed in the solution. Further, the plates were then removed from the cell and burnished; then replaced in the cell; and in the next five days, showed only the following change.

TABLE V.

\begin{tabular}{c|c|c}
\hline $\begin{array}{c}\text { No. of } \\
\text { Observation. }\end{array}$ & Interval. & Range of Apparent Resistance. \\
\hline 1 & 50 min. & 1.27 to 9.00 i. e., 7.73 ohms. \\
2 & 5 days. & 1.38 to 9.48 " 8.10 "“ \\
\hline
\end{tabular}

An investigation, as to whether this change is one of the electrodes or the solution, while of great interest, would, it was felt, carry us too far from the purpose of the work in hand, especially as a difficulty, not encountered with the copper, was met with here. It consisted in the difficulty of obtaining constant readings. The deflections would slowly increase, as they were repeated, becoming constant at last for a moment, and falling then to a lower point. If now the current were reversed, the resulting reading was at first much the lowest yet obtained. After several readings had been taken, it would pass through the same changes observed before reversing. It was thus constant at three points ; giving a minimum, a mean, and a maximum curve. Such a group of curves is given on Plate II., Fig. 3, Nos. VII., VIII., IX.

An explanation of the phenomena just described, in conformity to the theory of Wiedeburg, is quite possible. We need only assume that absorption of the ions by the electrodes occurs, to be in a position to understand these changes. When the first currents pass, absorption is large, and the resulting polarization is cut down. Repeated passing of the current in one direction fills the kathode, practically, and the polarization rises to the fixed value possible for the time and current employed. Meanwhile the anode is destitute of absorbed $\mathrm{Ag}$ ions, and hence in the best condition to absorb 
them. When, on reversing, it becomes the kathode, absorption is at its maximum value, and the resulting point on the $p$ curve has its lowest position. The process repeats itself indefinitely. In accordance with this supposition we should expect, if the supposition be correct, the best agreement with the formulæ in case of those observations taken where absorption is the least. That this is the case, reference to our data shows. I give below in Table VI. the values computed from a set of observations taken immediately upon putting the electrodes in the solution; and in Table VII. those taken from the maximum curve after the electrodes have been thirty days in the solution. Comparison will show that while the errors in $r$ in the former reach 20 per cent., in the latter they are less than 3 per cent.

\section{TABLE VI}

Ag in $\mathrm{AgNO}_{3}$. Nov. 26. T=19.2 ; $R=3.0$ ohms. Electrodes, $7.9 \times 12 \mathrm{~cm}$.

Solution, $100 \mathrm{G}$. in $1 \mathrm{~L}$. at $17^{\circ}$. $K=79.94 ; P=.0466 ; K P=3.72$.

\begin{tabular}{c|c|c|c|c|c|c|c}
\hline Cap. & $d C$ & $d R$ & \multicolumn{1}{c|}{$I$} & $\rho$ & $\left(\mathrm{x}-e^{-K I}\right)$ & $r$ & $P$ \\
\cline { 1 - 6 } 0.2 & 73 & 197.5 & .6488 & 1.11 & 1.0000 & 1.038 & \\
0.6 & 122 & 313.0 & .3405 & 1.17 & 1.0000 & 1.033 & .0431 \\
1.0 & 96 & 208.0 & .1358 & 1.38 & 1.0000 & 1.037 & .0493 \\
3.2 & 191 & 331.0 & .06745 & 1.73 & .9954 & 1.043 & .0474 \\
& 124.5 & 162.6 & .0333 & 2.30 & .9302 & 1.000 & \\
& 72.5 & 64.0 & .01306 & 3.40 & .6479 & 1.089 & \\
& 52.5 & 40.0 & .00816 & 3.93 & .4792 & 1.195 & \\
\hline
\end{tabular}

TABLE VII.

Ag in $\mathrm{AgNO}_{3}$. Jan. 2. $T=16.0^{\circ} ; \quad R=3.0$ ohms. Electrodes, $7.9 \times 12 \mathrm{~cm}$, 30 days in solution. Solntion $100 \mathrm{G}$. in $1 \mathrm{~L} . \mathrm{H}_{2} \mathrm{O}$ at $17.0^{\circ} . K=167.4 ; P=.0796$; $K P=13.4$.

\begin{tabular}{c|c|c|c|c|c|c|c}
\hline Cap. & $d C$ & $d R$ & $I$ & $\rho$ & $\left(\mathrm{x}-e^{-K I}\right)$ & $r$ & $P$ \\
\cline { 2 - 8 } 0.2 & 92 & 193.5 & .6317 & 1.43 & 1 & 1.304 & \\
0.4 & 103 & 200.0 & .3265 & 1.55 & 1 & .306 & \\
1.0 & 130 & 205.0 & .1339 & 1.90 & 1 & .305 & .07962 \\
3.2 & 273.5 & 327.0 & .0666 & 2.50 & 1 & .304 & .07961 \\
& 201.5 & 160.0 & .0327 & 3.78 & 1 & .339 & .07355 \\
& 158 & 63.0 & .0129 & 7.52 & 1 & .324 & .08471 \\
\hline
\end{tabular}

While the errors in the final values are far above those of observation, they are in accord with the assumption we have made. The 
observations were always begun with the large currents. If absorption occurs, with consequent depolarization, we should expect the greater effect with large currents; i. e., the values of $K$ and $P$ computed for the lower part will be too small to satisfy the upper part of the curve. While it is possible that a different arrangement in conditions, size of electrodes, concentration of solution, etc., might have given more concordant results, the difficulties in the way of using this metal for the purpose desired seemed too great to warrant its further trial at this time. The fine agreement of the values for the large currents, however, suggests the possibility of making this combination the basis of a later investigation as to the cause of the time change which occurs upon the standing of the electrodes in solution.

\section{Platinum Electrodes in Sulphuric Acid.}

Some observations, made in the earlier investigations by Dr. Guthe, with platinized platinum electrodes, showed a sufficient agreement with the formulæ to lead to the thought that, possibly, with bright electrodes, results might be obtained in good agreement with the theory. A number of observations with such electrodes were accordingly made at this point in the work, with the hope of getting rid of the time change in the range of apparent resistance. The results conform even less than had those with the platinized electrodes, to the requirement of a constant internal resistance.

The observed values for the internal resistance show changes from 5 to $160 \mathrm{ohms}$, with current changes from .6 to .0069 of an ampère respectively, in a single set of observations. While these reduce, by computation of $r$, to values ranging from $\mathrm{I} .43$ to 2.02 , the variations from a constant value are such as cannot be occasioned by experimental error. The same difficulty encountered with the silver was present here to a much greater degree, i. e., the creeping up of the deflections. ${ }^{1}$ Moreover, the time change in the range of apparent resistance was also present, as with copper and silver; a further indication that oxidation cannot be assigned as its cause. Table VIII. shows these changes.

This solution had been boiled to exclude air, and was covered with a layer of paraffin oil.

\footnotetext{
1 See also Guthe, 1. c.
} 
TABle VIII.

Bright Platinum in $\mathrm{H}_{2} \mathrm{SO}_{4}$. Time change in $\rho$.

\begin{tabular}{c|c|c|c|c}
\hline \hline Observation. & Temperature. & Interval. & Range. & Difference. \\
\cline { 2 - 3 } \cline { 3 - 4 } & 20.9 & 1 hour. & $5.29-165.0$ & 159.7 \\
2 & 22.5 & 12 hours. & $5.27-203.3$ & 198.0 \\
3 & 40.5 & 48 hours. & $5.16-211.5$ & 206.3 \\
\hline
\end{tabular}

The readiness with which platinum absorbs hydrogen, and the high value found for the polarization, are possibly chargeable with the variation here found; although the conditions are much more complicated than with a metal in a solution of its own salt. It is very interesting to note that, in spite of the ill agreement in the values for the internal resistance, the mean value obtained for the polarization, I. 88 volts, is in good accord with that found by other investigators. From the numerous data at hand upon this point, only the results from a single set will be given, showing the successive values for $P$.

TABLE IX.

Bright Platinum in $\mathrm{H}_{2} \mathrm{SO}_{4} . \quad T=38.3^{\circ} ; R_{1}=10.0$ ohms; $R_{2}, 30.0 ; K=134$; $P=1.88$.

\begin{tabular}{|c|c|c|c|c|c|c|c|c|}
\hline \multicolumn{2}{|c|}{ Cap. } & $d C$ & $d R$ & $I$ & $\rho$ & $\left(\mathrm{I}-e^{-K I}\right)$ & $r$ & $P$ \\
\hline \multirow{4}{*}{$R_{1}$} & .05 & 71.5 & 162.5 & .6366 & 4.40 & 1.0000 & 1.43 & 2.12 \\
\hline & .10 & 126.7 & 171.0 & .3350 & 7.41 & 1.0000 & 1.88 & 1.97 \\
\hline & .20 & 227.0 & 173.0 & .1695 & 13.10 & 1.0000 & 2.11 & 1.88 \\
\hline & .20 & 210.0 & 87.0 & .0852 & 24.14 & 1.0000 & 2.02 & 1.81 \\
\hline \multirow{4}{*}{$R_{2}$} & .30 & 298.0 & 211.0 & .0459 & 42.37 & .9979 & 1.53 & 1.56 \\
\hline & .30 & 257.6 & 105.2 & .0229 & 73.46 & .9535 & & 1.60 \\
\hline & .30 & 221.2 & 211.5 & .0138 & 104.58 & .8428 & & 2.26 \\
\hline & .30 & 173.5 & 105.6 & .0069 & 164.30 & .6030 & & \\
\hline
\end{tabular}

Zinc in $\mathrm{ZNSO}_{4}$.

A. Unamalgamated Plates.-It was with considerable interest that this part of the investigation was approached, owing to the conflicting testimony as to the polarization of this combination. For the sake of comparison only, a series of observations was first taken with the zinc unamalgamated. The plates were of the same size as the copper ones previously employed, $10 \times 13 \mathrm{~cm}$.; and the solution contained 25 G. c. p. zinc sulphate in I L. of distilled water. An observation was attempted as soon as the cell was set 
up; but the rapid time change made it impossible to complete it. To obtain an idea of the rate of this change, observations were taken

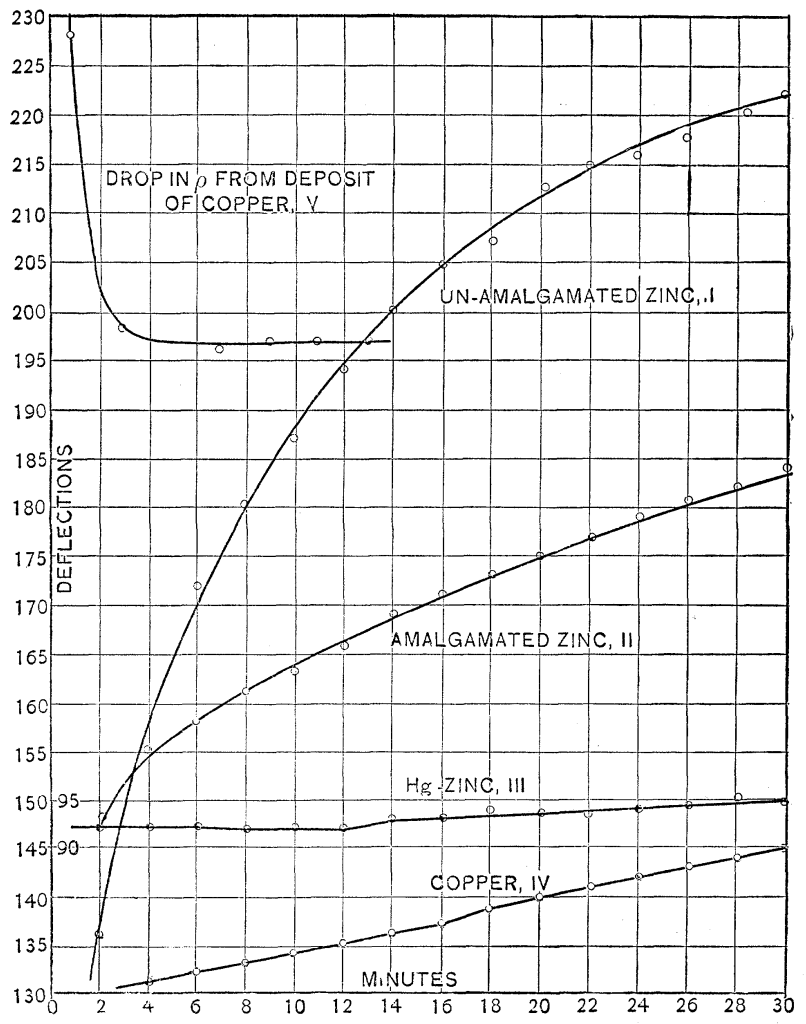

Plate I.

with large sensitiveness of the apparatus, every 20 seconds for half an hour. The results were plotted in the form of a curve, vide Plate I., No. I.

After the cell had stood undisturbed for two hours and a half it was found possible to take observations, although repeated swings of the pendulum would cut the deflections down from 3 to 5 scale divisions. The curves for these observations, Plate II., Fig. IV., Nos. X. and XI., are very instructive. The observations began with the smallest current used-at the point where the time curve had been taken 2.5 hours before. The currents were gradually in- 
creased to the largest used, and then returned to the original point. This order is indicated by the arrow heads upon the curves. These facts are evident: (a) the time curve shows an increase of 130 scale divisions in the first half hour, to which corresponds a change of

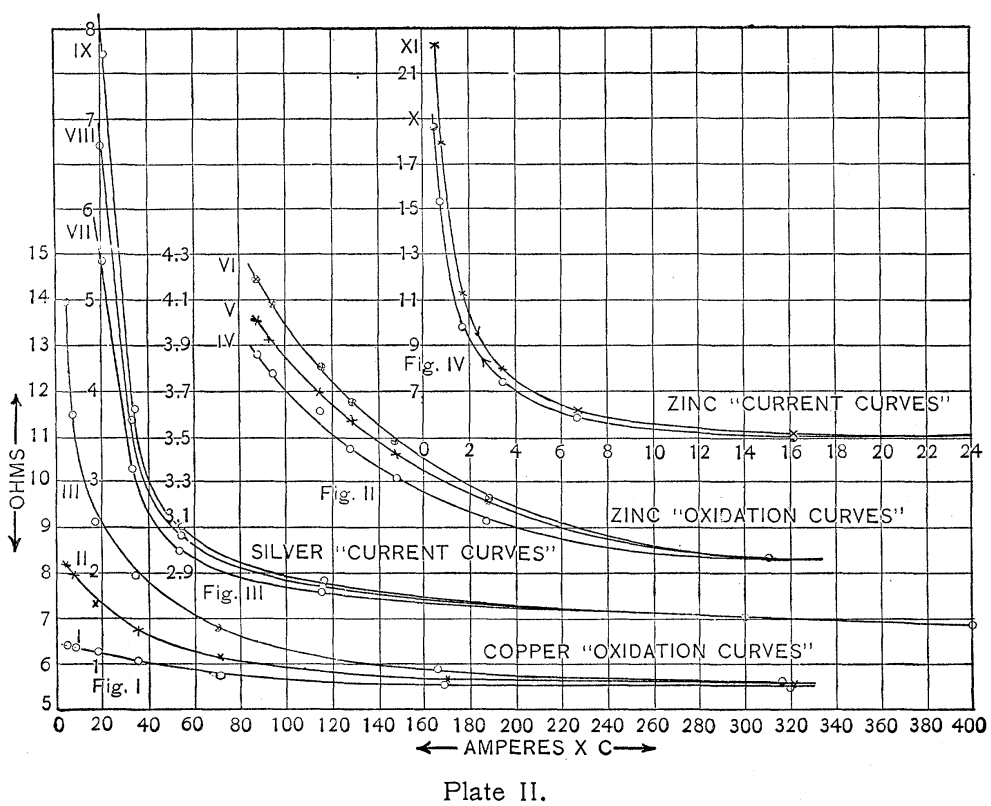

only I 7 divisions in the next 2.5 hours; (b) the use of large currents cuts down the apparent resistance to a marked degree.

The behavior of these electrodes, upon further standing in the solution, is shown in the following table.

TABLE X.

Time and Current Effect on $\rho$. Unamalgamated $\mathrm{Zn}$ in $\mathrm{ZnSO}_{4}$.

\begin{tabular}{c|c|c|c|c|c}
\hline $\begin{array}{c}\text { Hours } \\
\text { in the Cell. }\end{array}$ & $\begin{array}{c}\text { Starting Point, } \\
\text { with } \\
\text { Small Current. }\end{array}$ & $\begin{array}{c}\text { Minimum, } \\
\text { Largest } \\
\text { Current. }\end{array}$ & $\begin{array}{c}\text { End Point, } \\
\text { Smallest } \\
\text { Current. }\end{array}$ & Range. & Temp. \\
\hline 2.5 & 22.3 & 4.72 & 18.5 & 17.6 & 19.6 \\
24 & 32.0 & 3.97 & 23.3 & 28.03 & 17.4 \\
48 & 32.0 & 4.10 & 22.0 & 27.90 & 16.6 \\
\hline
\end{tabular}

Consideration of the results here shown makes it clear that, whatever the cause operating to increase the apparent resistance may be, 
it was in this case practically completed in the 24 hours after setting up the cell. Further, as with the platinum, silver and copper, we cannot conceive it to be an actual increase in resistance, due to an oxidation film. For here we have a cell in which the actual resistance, after 24 and 48 hours, is less than at the beginning; while the apparent resistance $\rho$ has increased its range 60 per cent.

While it was not to be expected that a combination, so susceptible as this, would give very accurate agreement with the formulæ, yet the computation of a set of observations is not without value for comparison with those of silver and platinum. Such a completed set follows in Table XI.

\section{TABle XI.}

$\mathrm{Zn}$ in $\mathrm{ZnSO}_{4}$. Jan. 7. Temp. $19.6^{\circ}$. $R=5.0$ ohms. Unamalgamated Electrodes, $10 \times 13 \mathrm{~cm} .2 \frac{1}{2}$ hours in solution. Solution, 26 G. C. P. ZnSO, in 1 Liter $\mathrm{H}_{2} \mathrm{O}$ at 20.0 degrees. $K=88.8 ; P=.1983 ; K P=17.7$.

\begin{tabular}{c|c|c|c|c|c|c|c}
\hline Cap. & $d C$ & $d R$ & $I$ & $\rho$ & $\left(x-e^{-K I}\right)$ & $r$ & $P$ \\
\cline { 2 - 8 } 0.2 & 295 & 312 & .6612 & 4.72 & 1.0000 & 4.40 & \\
0.2 & 162 & 160.5 & .3164 & 5.04 & 1.0000 & 4.41 & .1883 \\
0.5 & 198 & 168 & .1317 & 5.89 & 1.0000 & 4.39 & .2083 \\
0.9 & 222 & 151 & .0657 & 7.41 & .9971 & 4.40 & \\
1.0 & 169 & 84 & .0329 & 10.05 & .9462 & 4.36 & \\
1.0 & 103 & 33.6 & .0132 & 15.33 & .6896 & 4.81 & \\
\hline
\end{tabular}

It will be seen that, as with the silver, the resistance $r$ is constant until the smallest currents are reached. The same assumptions there made would suffice to explain these variations also.

B. Amalgamated plates. - It was at this point in the work that plates of varying areas were procured and observations upon them made. It was the intention to determine thus, at the same time, the conformity of the amalgamated plates to the theory, and the relation of the constants to the areas of the electrodes. The discussion of the latter question having been left for the second part of this paper, it is as well to defer to the same place the description of the preliminary work done with these plates, as it mainly was intended to bear especially upon that phase of the determination. It will be sufficient to give here the results bearing directly upon the question: Does Wiedeburg's formula satisfy the curves obtained with amalgamated zinc? 
Zinc plates, especially prepared for battery use, were procured, cleaned with some care, amalgamated, and investigated as follows: First, as with the unamalgamated zinc, a time curve was taken-vide Plate I., No. II. It was found that, even with amalgamated zinc, the same time effect is active: the apparent resistance increases merely from the standing of the plates in the solution.

Successive observations were then taken, as with the copper electrodes. The resulting curves are shown in Plate II., Fig. II., Nos. IV., V., VI., where they may be compared directly with those ob-

TABLE XII.

Amalgamated Zinc in $\mathrm{ZnSO}_{4}$. Time and Cnrrent Change in $\rho$.

\begin{tabular}{c|c|c|c|c}
\hline Observation. & Interval. & Range. & Difference. & Temperature. \\
\cline { 2 - 5 } \cline { 3 - 5 } 2 & 30 min. & $3.86-2.97$ & 0.89 ohms. & 19.0 \\
2 & “ & $4.13-3.07$ & 1.06 “ & 18.9 \\
3 & “ & $4.33-3.12$ & 1.21 “ & 18.8 \\
\hline
\end{tabular}

tained with the copper. There was a very slight increase here in the real resistance, only. I 5 of an ohm from the first to last observation. Part of this, if not all, is due to a fall in temperature of $0.2^{\circ}$. That better comparison may be possible, the curves have all been referred to the same starting point on the largest current used. The plates were only one eighth the area of those used, unamalgamated, and the solution was one containing 150 grammes in I liter, at $17.0^{\circ}$. The time consumed in taking the observations was one and a half hours. The range of increase of $\rho$ is shown in Table XII.

TABLE XIII.

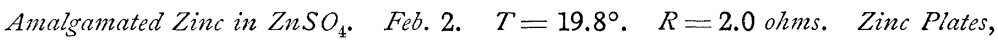
1. Solution (for all observations), $150 \mathrm{G}$. in $1 L$. $K=6.0 ; P=.0166 ; K P=.0996$.

\begin{tabular}{c|c|c|c|c|c|c|c}
\hline \hline Cap. & $d C$ & $d R$ & $I$ & $\rho$ & $\left(\mathrm{x}-e^{-K I}\right)$ & $r$ & $P$ \\
\cline { 2 - 8 } & 281 & 350 & .6835 & 1.606 & .9837 & 1.584 & \\
0.5 & 142 & 174 & .3408 & 1.632 & .8706 & 1.593 & .0179 \\
0.5 & 953 & 116 & .2275 & 1.643 & .7446 & 1.590 & .0152 \\
0.7 & 100.8 & 122 & .1707 & 1.651 & .6409 & 1.593 & .0118 \\
1.0 & 72 & 86.7 & .0849 & 1.661 & .3972 & 1.585 & \\
\hline
\end{tabular}

It will be seen that, even with well amalgamated zinc, the difficulties encountered with metals formerly used, are not avoided. 
While not so rapid in the first stages of the changes due to standing, the cell seems more susceptible to current effects; and gave often very indifferent curves. From the large number of observations, those given in tables XIII.-XVIII. are selected; showing to what degree the formula fits.

TABLE XIV.

Zinc Plates, 8. $K=17.4 ; P=.1162 ; K P=2.08$. Jan. 31. $T, 17.0 ; R, 3.0$ ohms.

\begin{tabular}{r|c|c|c|c|c|c|c}
\hline \hline Cap. & $d C$ & $d R$ & $I$ & $\rho$ & $\left(x-e^{-K I}\right)$ & $r$ & $P$ \\
\cline { 2 - 3 } .2 & 186.5 & 191 & .6236 & 2.93 & 1.0000 & 2.745 & \\
.2 & 100.8 & 97 & .3170 & 3.12 & .9960 & 2.749 & \\
.4 & 115.0 & 100 & .1632 & 3.45 & .9416 & 2.780 & \\
.7 & 146.0 & 119 & .1110 & 3.68 & .8551 & 2.777 & .1231 \\
.9 & 146.0 & 114.8 & .0833 & 3.82 & .7652 & 2.749 & .1159 \\
1.0 & 133.5 & 101.4 & .0662 & 3.95 & .6840 & 2.749 & .1096 \\
\hline
\end{tabular}

TABLE XV.

Zinc Plates, 16. $K=18.0 ; P=.1634 ; K P=2.88 . F e b .2 . \quad T=19.4 ; R=4.0$ ohms.

\begin{tabular}{c|c|c|c|c|c|c|c}
\hline Cap. & $d C$ & $d R$ & $I$ & $\rho$ & $\left(x-e^{-K I}\right)$ & $r$ & $P$ \\
\hline .1 & 105.5 & 129 & .6317 & 3.721 & 1.0000 & 3.014 & \\
.2 & 116.0 & 132 & .3208 & 3.515 & .9969 & 3.033 & \\
.3 & 127.8 & 136 & .2220 & 3.774 & .9816 & 3.037 & \\
.3 & 101.0 & 102 & .1665 & 3.961 & .9501 & 3.028 & .1669 \\
.4 & 112.0 & 108.8 & .1334 & 4.147 & .9094 & 3.027 & .1619 \\
.5 & 124.0 & 115.8 & .1134 & 4.283 & .8701 & 3.030 & .1613 \\
\hline
\end{tabular}

\section{TABLE XVI. ${ }^{1}$}

Amalgamated Zinc, $10 \times 13 \mathrm{~cm}$., in solution $\mathrm{ZnSO}_{4}, 25 \mathrm{G}$. in 1 Liter. Jan. 14. T, $24.0 ; R .=1.0$ ohm. $K=9.7 ; P=.03369 ; K P=.33$.

\begin{tabular}{c|c|c|c|c|c|c|c}
\hline Cap. & $d C$ & $d R$ & $I$ & $\rho$ & $\left(\mathrm{x}-e^{-K I}\right)$ & $r$ & $P$ \\
\hline 0.5 & 259 & 165 & .6464 & 1.57 & .9983 & 1.517 & \\
0.5 & 135 & 83.3 & .3263 & 1.62 & .9605 & 1.521 & .0333 \\
1.0 & 114 & 67 & .1312 & 1.70 & .7212 & 1.515 & .0334 \\
3.2 & 185.5 & 105 & .0643 & 1.77 & .4708 & 1.520 & .0343 \\
3.2 & 94 & 52 & .0318 & 1.81 & .2703 & 1.521 & \\
\hline
\end{tabular}

1 The curve showing agreement between observed and computed values for these observations, will be found on Plate III., No. III. 
TABLE XVII.

Amalsamated Zinc, $5 \times 6.5 \mathrm{~cm}$. Jan. $19 . T, 23.0 ; R, 3.0$ ohms. $K=20$; $P=.052 ; K P=1.04$.

\begin{tabular}{l|c|c|c|c|c|c|c}
\hline Cap. & $d C$ & $d R$ & $I$ & $\rho$ & $\left(1-e^{-K I}\right)$ & $r$ & $P$ \\
\hline 0.2 & 104.5 & 202 & .6594 & 1.55 & 1.0000 & 1.489 & \\
0.2 & 56 & 102 & .3330 & 1.65 & .9987 & 1.491 & .05331 \\
0.9 & 116 & 191 & .1386 & 1.84 & .9381 & 1.488 & .05070 \\
1.0 & 132 & 214 & .1397 & & & & \\
1.0 & 42 & 106 & .0686 & 2.04 & .7462 & 1.492 & .05146 \\
3.2 & 123.5 & 166 & .0339 & 2.23 & .4921 & 1.479 & \\
3.2 & 52.5 & 65 & .0134 & 2.42 & .2356 & 1.484 & \\
\hline
\end{tabular}

TABle XVIII.

Amalgamated Zinc Plate $2.5 \times 6.5 \mathrm{~cm}$. Jan. $21 . \quad T, 23.0 ; R, 5.0$ ohms. $K=20$; $P=.0676 ; K P=13.5$.

\begin{tabular}{l|c|c|c|c|c|c|c}
\hline Cap. & $d C$ & $d R$ & $I$ & $\rho$ & $\left(\mathrm{r}-e^{-K I}\right)$ & $r$ & $P$ \\
\hline 0.2 & 276 & 312 & .6112 & 4.437 & 1.0000 & 4.311 & \\
0.2 & 145 & 161 & .3154 & 4.503 & .9982 & 4.290 & .0691 \\
0.5 & 160 & 168 & .1324 & 4.762 & .9292 & 4.260 & .0683 \\
1.0 & 171 & 170 & .0666 & 5.029 & .7329 & 4.326 & .0702 \\
3.2 & 281 & 265.3 & .03248 & 5.296 & .4777 & 4.301 & .0627 \\
& 114 & 104 & .01273 & 5.481 & .2249 & 4.288 & \\
& 72 & 65 & .00796 & 5.538 & .1471 & 4.290 & \\
\hline
\end{tabular}

